\title{
AMBIGÜEDAD Y EROTISMO
}

\section{LA TRADICIÓN DEL ROMANCERO EN EL DE AMORE}

\author{
AMBIGUITY AND EROTICISM \\ The tradition of the romancero in the De Amore
}

AMBIGÜIDADE E EROTISM.

A tradição do romancero no De Amore

\author{
Patrizia Di Patre \\ (Pontificia Universidad Católica del Ecuador) \\ pdipatre@puce.edu.ec
}

Recibido: 22/11/2021

Aprobado: 20/12/2021

\begin{abstract}
RESUMEN
A lo largo del romancero se intersecan líneas y focos de reflexión cuyo sustrato bien puede haber ocasionado las principales temáticas y giros indagatorios del tratado compuesto por Capellanus. Con este trabajo se pretende explorar las intersecciones teóricas, principalmente bajo la forma de directrices éticas y simbólicas, entre el volumen de Capellanus y el conjunto de romances presentes en la colección renacentista, con el fin de localizar sus antecedentes tempranos en época medieval y determinar al mismo tiempo las fuentes de inspiración temática propias del tratado compuesto por Andrés el Capellán.
\end{abstract}

Palabras clave: Capellanus, romancero, amor cortés, Edad Media, poesía medieval.

\section{ABSTRACT}

Throughout the Romancero lines and foci of thoughts intersect, which may well have caused the main themes and investigative turns of the treatise composed by Capellanus. The work aims to explore the theoretical intersections, mainly in the form of ethical and symbolic guidelines, between the Capellanus volume and the set of romances present in the Renaissance collection, to locate their early antecedents in medieval times and determine at the same time the sources of thematic inspiration typical of the treatise composed by Andreas Capellanus.

Keywords: Capellanus, romancero, courtly love, Middle Ages, medieval poetry. 
Ao longo do romance, linhas e focos de reflexão se cruzam, cujo substrato pode muito bem ter dado origem às principais voltas temáticas e investigativas do tratado composto por Capellanus. O objetivo deste trabalho é explorar as interseções teóricas, principalmente na forma de diretrizes éticas e simbólicas, entre o volume de Capellano e o conjunto de romances presentes na coleção da Renascença, a fim de localizar seus antecedentes iniciais na época medieval e ao mesmo tempo determinar as fontes de inspiração temática do tratado composto por Andrés el Capellán.

Palavras-chave: Capellanus, romances, amor cortês, Idade Média, poesia medieval.

\section{Introducción}

Todo lo relacionado con el patrimonio retórico amoroso, incluidas las valencias simbólicas, tiene cabida en los tres libros del célebre tratado compuesto por Andrés el Capellán ${ }^{1}$; a veces un simple giro locutorio ("de la cintura para arriba, de la cintura para abajo") conlleva filones de expansión inusitada, hasta llegar a casuísticas muy sutilmente complicadas; en otras ocasiones, un epílogo clásico o lugares comunes bastante difundidos estarán sujetos a operaciones de alta conceptualización. Detrás de este aparato impuesto por la tradición cultural hay, sin embargo, un empleo muy consciente y sistematizado: todos los tópoi con implicaciones negativas para la mujer y las libres expresiones de un amor pasional aparecen recogidos, en los primeros dos libros, con vistas a una refinada inversión. Así acontece con el tópico de la mujer víctima, abundantemente presente en el Cancionero $^{2}$; con el de la mujer habladora e insidiosamente liosa; con el motivo opuesto al de víctima inocente, o sea la mujer que asesina a sus rivales $^{3}$. Hasta las sentencias neutras relativas a los hierros que, por amor, se deben perdonar, reciben en las diatribas del Capellán ostentosas amplificaciones apologéticas: no hay hierros en la fuente de todo bien.

En el tercer libro, en cambio, la recogida de la tópica tradicional reitera las funciones primitivas, acentuándolas en formas, también aquí, sistemáticas y consecuenciales. El libro medieval sobre el amor comienza como una quaestio: con definiciones previas a la argumentación ${ }^{4}$. Se confronte el accessus del tratado amoroso con el de Dante sobre la Monarquía $^{5}$, para sancionar irrefutablemente la analogía argumentativa y aquiescencia semántica de ambos referentes:

Primum igitur videndum quid est quod "temporalis Monarchia" dicitur, typo ut dicam et secundum intentionem". Est ergo temporalis Monarchia... unicus principatus ${ }^{6}$.

\footnotetext{
1 La referencia para el De Amore será la edición de Walsh P.G (1982). London: Duckworth. La casi totalidad de pasajes, sin embargo, se presentará en una traducción al español de mi autoría.

2 Me remitiré al romancero a través de dos ediciones: la de Díaz-Mas: (1994). Romancero. Barcelona: Editorial Crítica (pero solo en contadas ocasiones); la selección operada por Alvar, M. (1984). Romancero. Barcelona: Bruguera. Indicaremos la edición de Díaz-Mas como Romancero [1]. Sobre el carácter tradicional y la propagación de los materiales contenidos en el romancero, es imprescindible la lectura de Alvar, M. (1970). El romancero. Tradicionalidad y pervivencia. Barcelona: Planeta.

3 Sobre estas tipologías, variamente interpretadas o revisitadas, se vean los siguientes textos:

Anahory-Librowicz, O. (1989). Las mujeres no-castas en el romancero: un caso de honra. En S. Neumeister, Actas del IX Congreso de la Asociación Internacional de Hispanistas (pp. CCCXXI-CCCXXX). Madrid: Vervuert; Cano, B. (2004). Las mujeres malas en el Romancero. En Líneas actuales de investigación literaria: estudios de literatura hispánica (pp. LXIII-LXXI). Valencia: Universidad; González Troyano, A. (1989). Algunos rasgos del arquetipo de la mujer seductora en el romancero tradicional andaluz. En Pedro M. Piñero Ramírez, El Romancero. Tradición y pervivencia en el siglo XX. Sevilla: Fundación Machado de Cádiz.

4 Con relación a esto, véase Di Patre: (2018). A la sombra del De Amore. Dante entre Capellanus y La Celestina. Celestinesca, 42, 57-82. Ahora, en ese artículo no se ponen suficientemente de relieve las fórmulas proemiales caracterizadoras de un tratado científico y obedientes a la misma finalidad disquisitiva: "quid sit amor, et unde dicatur amor, et quis sit effectus amoris, et inter quos possit esse amor, qualiter acquiratur amor, retineatur, augmentetur, minuatur, finiatur": cfr. De Amore, op. cit., I, Accessus ad amoris tractatum.

5Alighieri, D. (1979). Opere minori, II. Monarchia. B. Nardi (Ed.). Milano-Napoli: Ricciardi.

6 Monarquía, I, 2,1. La definición, lejos de agotarse aquí, continuará en los mismos términos que en el tratado amoroso, considerando la finalidad, la extensión, los medios, los actores, etcétera. Véase el artículo de Di Patre: (2018). Dalla Monarchia di Dante al trattato machiavelliano sul Principe: un percorso obbligato. Dante. Rivista internazionale di studi su Dante Alighieri , XV, 11-28.
} 
Considerado el manantial de términos tradicionales constituido por el romancero (con la recogida sistemática que impone), asumiremos esta colección como referente universal de nuestra búsqueda, señalando siempre el valor antagónico u homológico, pero en todo caso fontal, de un thesaurus que debió de circular en términos cronológicamente cercanos a los de nuestro autor medieval. Esto consentirá también separar los componentes del caudal común (previo, por ende, a ambas obras, o contemporáneo del solo Andrés) de otros factores unívocamente caracterizadores.

\title{
"De la cintura arriba, de la cintura abajo": un empleo común
}

Para ver el carácter siempre amplificante -también en módulos "neutros"- de locuciones o símbolos que resultan peculiares en el referente asumido, bastará remontarse al Romance del conde Claros de Montalván ${ }^{7}$, que podríamos considerar como un contenedor universal de dichos y hechos atinentes a las formas tradicionales del amor cortés-descortés ${ }^{8}$.

Media noche eran por filo, los gallos querían cantar,

conde Claros con amores no podía reposar:

dando muy grandes sospiros que el amor le hacía dar,

por amor de Clarañina, no le deja sosegar (108, 1-4).

El conde se viste de una forma particularmente elegante, va a buscar a la amada presa de un ímpetu irresistible, le habla en formas corteses que despiertan la simulada burla de la mujer: "Conde Claros, conde Claros, el señor de Montalván, / ¡cómo habéis hermoso cuerpo para con moros lidiar!”. Este motivo, tópico en el romancero ${ }^{9}$, será recogido por el Capellán únicamente en la forma completa del elogio omnicomprensivo: bueno en el amor, valeroso en armas, conocedor de todas las artes, excelente en el juego, dulce y manso, de extrema generosidad para con todos, etcétera (cfr. de entre los innumerables lugares el extenso y ejemplar presente en I, 142-161). Conjunto modélico, núcleo de paralela expresividad dentro del romancero: "Tan apuesto de persona, decidor bueno entre damas, / repartidor en su haber, aventajado en la lanza" ${ }^{10}$.

Hay versiones más o menos extensas:

\begin{abstract}
El cual desque fue mancebo muy esforzado salía:/ de gran corazón y seso e ingenioso a maravilla,/ de hermoso cuerpo y cara que nada le fallecía; / daba muy buenos consejos a quien menester lo había/ hombre de buena palabra y de buen donaire y guisa, / pagábanse mucho de él, amábanle en demasía/ todos los homes del mundo que por caso le veían./ Sobre estas buenas maneras otras dos gracias tenía: / que era gran cabalgador, si en todo el reino lo había; / gran lanzador de tablados que mucho bien lo facía;/ tenía muy buenas armas obraba caballería/ tan altamente con ellos, que todos temor le habían;/ nunca se falló en batallas que de ella bien no salía (Romance del conde don Sancho Díaz, 10, 54-66).
\end{abstract}

En el contexto del romance que escogimos (Romance del conde Claros de Montalván), los términos emblemáticos del cuadro (buen peleador, amador óptimo) se encuentran concentrados de forma peculiar: "Mi cuerpo tengo, señora, para con damas holgar: / si yo os tuviese esta noche, señora a mi mandar, /

\footnotetext{
${ }^{7}$ Las citas proceden siempre en conformidad con la selección operada por Alvar, M. (1984). Romancero. Barcelona: Bruguera, salvo indicación en contrario (Romancero, [1]).

${ }^{8}$ Sobre este tema, véase en primer lugar el volumen ya clásico de Cherchi: (1994). The Ambiguity of Courtly Love in Andreas Capellanus's Model. Toronto: University Press; Martínez, N. (2015). Andrés el Capellán ante el fenómeno del amor cortés. Studium. Filosofia y Teología, 35, 101-107; Paolini, D. (2010). El libro de buen amor y el amor descortés. En P. Civil, F. Crémoux, Nuevos Caminos del hispanismo. Actas del XVI Congreso de la Asociación Internacional de Hispanistas, 2 (pp. XXXXVI-LII). Madrid: Iberoamericana.

${ }^{9}$ Complementario a la oposición entre juegos de amor y armas: ("Caballero que va en armas de mujer no debe curar": Romance del conde Dirlos, 115). Cfr. 26 (Retos de los dos caballeros zamoranos), 17-21: "Mientras los condes se arman, el padre al hijo ha hablado: / "Tú bien vees, hijo mío, aquellos tablados altos / donde dueñas y doncellas nos están de allí mirando: / si lo haces como bueno, serás de ellas muy honrado; / si lo haces como malo, serás de ellas ultrajado".

${ }^{10}$ Lo tomamos de la edición paralela: Romancero [1] de Díaz- Mas: (1994). Barcelona: Editorial crítica. Llanto de Gonzalo Gustioz, III, 47-48.
} 
otro día en la mañana con cien moros pelear, / si a todos no los venciese que me mandase matar" (108, 30-33).

Suficiente reunión de motivos, como para alertar sobre la presencia de una tópica ejemplar. Vayamos ahora al núcleo que despertó nuestro interés, es decir, la caracterización topográfica de los goces amorosos:

Tomárala por la mano, para un vergel se van; / a la sombra de un ciprés, debajo de un rosal, / de la cintura arriba tan dulces besos se dan, / de la cintura abajo como hombre y mujer se han $(108,46-49)$.

Todo en este romance es ambiguo: al cazador que presenció la escena, y lealmente se la refiere al padre de la Infanta, denominado siempre en el texto "el buen rey", se le da muerte despiadadamente, como a tantos otros portadores de malas nuevas: y eso que no cuidó de los extraordinarios sobornos ofrecidos para callar, como se subraya en el cuerpo narrativo; todos corren el riesgo de morir: el conde, degollado; la infanta, de dolor y espanto. Pero el final es feliz, puesto que "quien no ama las mujeres no se puede hombre llamar", y "que los yerros por amores dignos son de perdonar": en el más puro espíritu de Andrés, el de la primera parte o de los libros I y II, naturalmente. Se confronte a este propósito el lugar que sigue inmediatamente a una carta sentenciosa de la duquesa de Champagne (I, 395-400), donde el "más noble" habla, precisamente, "a la más noble":

Sin embargo creo que en el amor no puede haber grave ofensa a Dios, porque con leve pena puede expiarse el pecado cometido por natural necesidad; y también porque no es absolutamente lícito el considerar pecado lo que origina en esta vida el bien sumo, sin el cual nadie en el mundo podría considerarse digno de alabanzas ${ }^{11}$.

No extraña por ende, a tenor de ambos textos, que la figura en cuestión, "de la cintura arriba, de la cintura abajo" sea objeto de una cumplida disertación teórica a lo largo de nuestro tratado (I, 533-560), y precisamente al final de este diálogo. Es la mujer quien interpela al varón sobre el caso de una mujer "extraordinariamente gentil", la cual les da a escoger a dos rivales entre la posesión de "la parte alta o baja" de su cuerpo. ¿Quién ha elegido la parte mejor, y por ende el más cumplido legado, del cuerpo femenino?

Profanaciones aparte (ya que nadie negaría aquí el paralelo religioso entre Marta y María, con la explícita referencia a quien escoge "la parte mejor" de la herencia cristiana), o más bien perfectamente insertas en el tejido discursivo de Andrés, se ha de conjeturar en este punto una tópica de muy consolidada tradición: señas claras de ello son las frases declaratorias del lugar común, exentas de cualquier precisión o indicios, simplemente ligadas a un concepto que, en virtud de lo mismo, no necesitaba mayores aclaraciones; se resumía así, de forma escueta o altamente alusiva.

La otra línea tradicional es más de tipo lingüístico que simbólico, o tal vez resume ambos propósitos: se trata de la locución sustitutiva, pero también referencial con respecto a un uso punitivo real, del "cortar las faldas por vergonzoso lugar" 12 (cfr. Romancero, 18: Romance de doña Lambra), probablemente ligado a un paralelo masculino de indudable "punibilidad" en términos cristianos:

\footnotetext{
"Dios es en la ayuda mía", / respondió el buen rey Rodrigo, / "la culebra me comía, / cómeme ya por la parte que todo lo merecía, / por donde fue el principio de la mi muy gran desdicha" (Romancero [1], Penitencia de don Rodrigo, 27, 53-56).
}

\footnotetext{
${ }^{11}$ De Amore, I, 417-8: traducción mía, como en todos los contextos que siguen.

${ }^{12}$ Cfr. Cherchi: (2016). “Acursar les faldes”. Postilla al Tirant Lo Blanch, cap. XIV. Studi Romanzi. Nuova serie, 12, $233-243$.
} 
Son señales verbales impregnadas de un rigorismo costumbrista, o constitucional diríamos (dado su carácter socionormativo), contrahechas dentro del tratado medieval hasta la inversión más desenvueltamente paródica: lo que en términos tradicionales denuncia la culpa y merece un castigo, se convierte aquí en una topografía idealmente erótica, en fantásticas coordenadas del placer.

\section{Mujer víctima, mujer asesina ${ }^{13}$}

En el romancero el tema de la mujer víctima, muerta a manos del marido, hace esporádicas, pero muy significativas apariciones. La más cumplida realización del motivo la tenemos en el Romance de cómo el duque de Berganza mató a la duquesa su mujer: "Revolvió el duque su espada, a la duquesa hería: dióle sobre su cabeza, y a sus pies muerta caía $(53,29-30)$.

También el Romance del rey don Pedro toca, aunque de manera realmente fugaz, esta dramática incidencia:

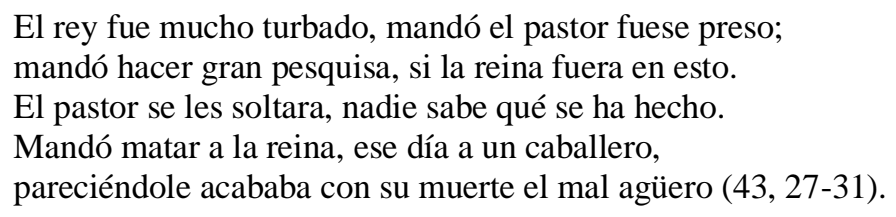

En otro romance muy señalado, el del conde Alarcos, tenemos un núcleo temático que conjuga dos funciones a la vez, la que se está examinando y la antitética conectada con la imagen de la "mujer asesina", inspiradora de homicidios por amor, o celos. Lo examinaremos en la clave correspondiente, ya que por ahora urge considerar el desarrollo del motivo expuesto en el tratado De Amore. Si bien el tercer libro de la obra teoriza la eventualidad en cuestión, en el resto del volumen falta toda alusión a la idea. Eso se debe a que mientras el Capellán considera siempre el rol honorífico de la mujer, y busca atribuirle constantemente un papel fundamental o inclusive dominante, dentro de la sucesiva reprobatio amoris no cabe sino el rechazo a lo contrario: la violencia sobre la mujer cobra entonces aspectos meramente acusatorios o contrastivos, sin minar la pasividad inherente al sujeto:

Para colmo sabemos de muchos que, llevados por el excesivo amor a sus amantes, no solo meditan en delitos nefandos, sino que hasta llegan a trucidar cruelmente a su propia mujer; y a todos consta que el delito es cosa infame (III, 44).

Siempre en el tercer sector de la obra, y en franca reprobación de amor, el paralelo de la asesina -o hembra presta para cualquier atrocidad- tan presente a lo largo del romancero, cobra un relieve muy particular:

Es además la mujer siempre prona a cualquier atrocidad; cualquier delito, por atroz que sea o se haya podido manifestar en este siglo, cada mujer sin excepciones ni temor alguno, movida por razones nimias, comete de ordinario.

\footnotetext{
${ }^{13}$ Sobre el motivo de la caracterización femenina en el romancero, véase el trabajo de Villas Millanes G.(2020). La mujer en el romancero: una propuesta de análisis tipológico de los personajes femeninos. [Disertación de grado, Universidad de Zaragoza]. https://zaguan.unizar.es/record/94789/files/TAZ-TFG-2020-1108.pdf?version=1.

Se puede consultar también Lacarra Lanz, M.E. (1993). Representaciones de mujeres en la literatura española de la Edad Media (escrita en castellano). En Iris M. Zavala, Breve historia feminista de la literatura española en lengua castellana, 2, (pp. XXI-LXVIII). Madrid: Anthropos.
} 
¿Cómo no pensar en las “infantas” del romancero, justicieras atroces de sus rivales? Veamos esto:

Yo os lo daré, buen Rey, d'este poco que tenía:

mate el conde a la condesa que nadie no lo sabía

y eche fama qu'ella es muerta de un cierto mal que tenía

y tratarse ha el casamiento como cosa no sabida

(Romancero [1],72, 46-49).

El mismo motivo, dominado por un desenfado análogo, campea en el Otro romance de doña Isabel (51). La protagonista aquí es nada menos que la despiadada reina, la cual manda matar a la concubina del rey: ella tiene hijos de él, y su culpa consiste en eso a los ojos de la soberana. Sin tener en cuenta nada más que su propio enojo ("[el Rey] por fuerza me fue a tomar", se defiende sin éxito doña Isabel), la mujer planea fríamente este acto execrable. Escuchemos las palabras de la triste embajada:

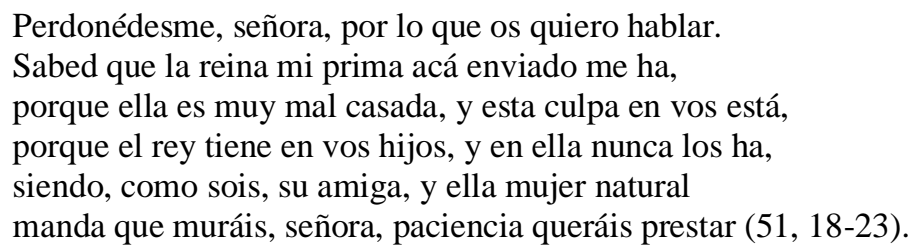

Llegaremos a la conclusión de que en el tercer libro del De Amore se recogen los motivos denigratorios acerca de la figura femenil (y masculina también), mientras que en el resto del tratado seguimos constatando la más absoluta desautorización de la tópica atinente al género: notemos en efecto que el lugar común tradicional y sobresaliente de los primeros libros, o sea la consideración de la mujer como fuente de todo bien, objeto de admiración perpetua y, sobre todo, refinada decididora de cualquier cosa -y de su destino en primer término-, falta absolutamente en la tradición que alimentó el romancero. Discursos como los que siguen serían impensables desde la perspectiva invariable de los romances:

Creo por cierto que los hombres de bien han sido dispuestos por Dios con el único fin de obsequiar a señoras como vos sois, obedeciendo sus voluntades, y me parece patente por la fuerza de indudables razones que los hombres en sí nada pueden, ni sacan algún provecho de la fuente de todo bien, si no es por sugestión de las damas (I, 403).

Aunque todos los bienes proceden sin duda de las mujeres, y muchas prerrogativas les ha concedido el Señor, y ellas son consideradas fuente y origen del propio bien... (I, 403).

La preceptiva del amor cortés excluye cualquier tradición porque es originalmente promotora de un nuevo, o más bien inusitado, filón tradicional. Esta tradición incipiente crea ex nihilo sus propios tópicos -destinados a ser tales-, reinventa posiciones, destruye cualquier creencia contraria en nombre de un evangelio propio, de ilustres distanciamientos y posturas francamente anómalas. Cuando, en cambio, querrá retomarse un posicionamiento "burgués", no se dudará nada en escoger los módulos de más potente tradicionalismo, los que impregnan profundamente las vetas de innumerables canteras populares, o más que populares: romantizados y en versos... 


\section{Mujer facunda, mujer astuta}

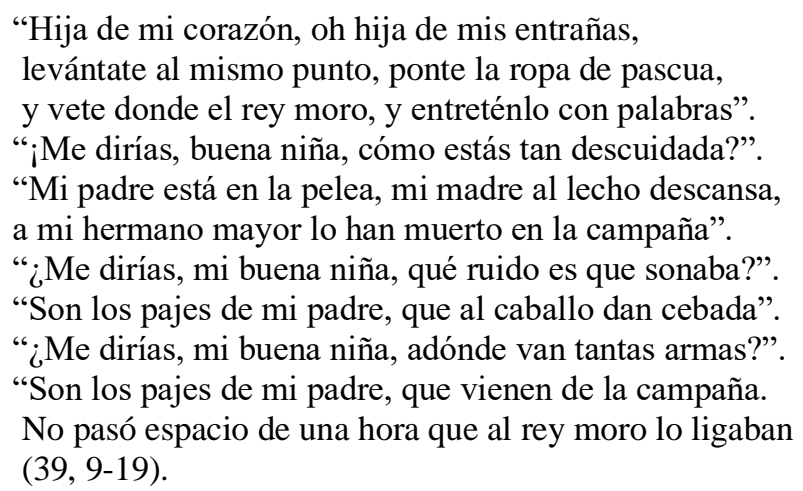

El motivo tópico de la mujer sagaz y parlanchina, tan difuso en el romancero, aparece variamente trabajado a manos del Capellán. Veamos entre todos este empleo significativo:

Mucho cuidado debes tener, Gualterus, en no dejarte engañar por la vana hermosura de las mujeres, pues son tales su astucia y facundia que no te será fácil, una vez gozados sus favores, desprenderte de su amor (I, 10).

Es obvio que, a diferencia del romancero donde el tema es extremamente variegado -como veremos enseguida-, aquí solo tenemos una doble polaridad: blanco o negro, rechazo o acogida. En general las palabras de la mujer son siempre más elegantes, refinadas y concluyentes que las del varón; y se puede percibir incluso un dejo de ironía en este juicio de la mujer plebeya hacia las dotes oratorias del otro sexo: “...: magisque placent ab homine verba prolata quam pica loquente" (I, 171). Las protagonistas de los diálogos se muestran más diestras también en el empleo de las fórmulas escolásticas, y el hombre debe frecuentemente ceder a la fuerza de sus razones ${ }^{14}$. Ahora, de todo ello la mujer saca buen partido y con tanta determinación, que no duda en aplastar al interlocutor mediante un bien calculado sarcasmo: "En tus discursos te muestras como un cangrejo, siempre andando en reversa, ya que no temes renegar de lo que antes afirmabas con tanto entusiasmo" (I, 188); “Tu argumento entonces se desploma bajo el peso de evidentísimas razones" (365).

Por otra parte, el escuadrón de las mujeres "nobilísimas" está compuesto por las que "supieron dar respuestas dignas a quienes insidiosamente las requería de amores" (243), como muestran también en el romancero los ejemplos que siguen. La conclusión es que, de todo el caudal perceptible en el filón amoroso popular, lo más elogioso se recoge en los dos primeros libros del Capellán; y que todo cuanto se recoja en tal sentido será rotundamente desmentido en el tercero:

Que nunca la mujer puede detenerse en su habla, y ni el espíritu ni la lengua se cansarían jamás en ello. Y hasta se sabe de mujeres que, no teniendo con quién hablar, se hablan a sí mismas y en voz alta, por la mera avidez de proferir palabras" (III, 100-101).

Pero vayamos ya a los paralelos "buenos" del romancero:

\footnotetext{
"Calledes, conde, calledes, y no os queráis alabar; el que quiere servir damas así lo suele hablar, y al entrar en las batallas bien lo saben excusar (108, 34-36).
}

${ }^{14}$ Confronta en el artículo citado de Di Patre, P (2018). A la sombra del De Amore: 67. 
Se debe notar aquí el más puro espíritu del Capellán, en un romance que hemos considerado precisamente por estar en clara sintonía con las reglas de amor manifestadas en el tratado medieval. La "burla" es un componente ineludible de las escaramuzas amorosas, como veremos también en el próximo apartado ${ }^{15}$.

\section{Mujer burladora}

Ahí habló el caballero, bien oiréis lo que decía:

“¿De qué vos reis, mi alma? ¿De qué vos reis, mi vida?”.

La niña que estaba en salvo, aquesto le respondía:

"Ríome del caballero y de su gran cobardía, que tiene la niña en el monte, y usaba de cortesía"

(Caballero burlado, 139, 26-29).

La niña desque lo oyera díjole con osadía:

"tate, tate, caballero, no hagáis tal villanía:

Hija soy de un malato y de una malatía;

El hombre que a mí llegase malato se tornaría".

A la entrada de París la niña se sonreía:

“¿De qué vos reis, señora, de qué vos reis, mi vida?"

"Ríome del caballero y de su gran cobardía, ¡tener la niña en el monte, y catarle cortesía!

Caballero, con vergüenza, estas palabras decía [...]

(Romance que dice: de Francia partió la niña, 140, 12-21).

La niña le respondiera y estas palabras decía:

“ $\mathrm{Oh}$ mal haya el caballero que sola deja la niña!

Él se va a tomar consejo, y ella queda en la montaña"

(Romance de la infantina, 138, 15-17).

Este último tema en realidad se cruza con el de la "mujer discreta", bien hablada y sentenciosa. Así que una vez más notamos el sapiente dominio por parte del Capellán de todos los filones relativos al ensalzamiento o denigración de la figura femenina.

\section{3. "Ella, como discreta, no creyó en sus dichos"}

Ocurre muchísimas veces que la mujer "requerida de amores" no confíe en las palabras del interlocutor, ya sea porque se cree indigna de él, por motivos esencialmente ligados a la respectiva posición social, o porque le interesa más desentenderse del asunto. En otras ocasiones pueden manifestarse actitudes francamente retóricas, y no es siempre fácil decidir entre las distintas manifestaciones en juego. El modelo genérico se atañe, de todas formas, a nociones básicas, establecidas de la forma que declaran los siguientes versos:

La cava, como es discreta, a burlas lo había echado.

El rey le hace juramento que de veras se lo ha hablado.

Todavía lo disimula, y burlando se ha excusado

(Romance de la Cava, 4, 7-9).

El módulo funciona también con los referentes invertidos (quien requiere y puede burlar es una mujer), según lo veremos en el ejemplar Romance de Gerineldo: "Como soy vuestro criado señora, os burláis conmigo" (Alvar 94, 3). Y esto da pie para hablar de la libre utilización del canon por parte de Andrés. $\mathrm{El}$ autor se apresura en efecto a establecer la igualdad de condiciones en el ofrecimiento de amor, como sucede con tanta frecuencia a lo largo del romancero:

\footnotetext{
${ }^{15}$ Antes de ir más adelante en el análisis de estas modalidades, será conveniente ampliar la temática y reenviar al esclarecedor artículo de Botta: (2013). El léxico del Romancero General de 1600. Edad de oro, 32, 47-78.
} 
Puede entonces la mujer, cuando alguien la convida a amar, alentarlo con gracia y cortesía, si se da cuenta de que el otro por alguna razón no manifiesta su amor. A este argumento por lo demás le confiere gran autoridad el testimonio de la hija de Carlomagno, quien abiertamente requirió de amores a Hugo de Alvernia (I, 517).

Podemos apreciar con esto el tipo de ambiente y las auctoritates involucradas en el proceso, con todo lo que comporta en términos de derivación literaria. La fuente de todo ello debe necesariamente ser común.

Volviendo al tópico de la burla amorosa y al temor relacionado de caer en alguna trampa, aquí tenemos un magnífico ejemplo: "Siempre os preciasteis, conde, de las damas os burlar" (Romance del conde Claros, 40). Ahora, el prototipo en cuestión subsiste, a diferencia de otros casos, en el solo romancero, ya que a manos del Capellán el motivo se encuentra muy sutilmente trabajado y enriquecido, como era de esperar dado su preeminente papel en el juego conversatorio de las partes ${ }^{16}$. Se puede llegar inclusive al grado de refinamiento presente en estas líneas:

El amador sapiente y entrenado no debe, en su primer coloquio con una dama desconocida, solicitar directamente favores amorosos, sino que primero debe darse a conocer, y en segundo lugar mostrar en todos sus discursos una suave apacibilidad (I, 353).

Una declaración directa es sospechosa; para evitar la trampa del diálogo mendaz se debe recurrir a un instrumental potentemente codificado, gracias al cual el primitivo eslabón de la mentira da lugar a una expresividad sin dobleces. En tales condiciones se fijan solo esquemas procedimentales, destinados a convertirse después en tablas de verdad específica, o sea amorosa. Cuando los interlocutores incurren en el caso señalado de la burla inherente a la disparidad social, todo se resuelve de forma inesperada, con una elegancia lógica que reemplaza cualquier eventualidad maliciosa. Y es que disponen de cánones:

Sería verdaderamente feliz la plebeya que se hiciera digna del amor de un conde; mas pensad cuál alabanza o premio le correspondiera al conde, o marqués, que aspirara a obtener el amor de una plebeya (I, 285).

Cesa o decae entonces el propio origen de la eventualidad burlesca, que puede residir solo en espacios ajenos al reinado del amor. Es claro que el primitivo tema de los romances ha proporcionado únicamente, en el caso presente, el pretexto para disolverlo todo.

\section{Requeridora de amores, requerida}

Aquí también la doble eventualidad en cuestión, lejos de representarse fielmente, deriva en sutilezas aclaratorias. Pero el tema existe, surge la necesidad de reseñarlo, proporciona soluciones nuevas a núcleos de problematicidad incipiente. Veámoslo a partir del romancero:

\footnotetext{
“QQué mandáis, gentil mujer?”.

Con una voz amorosa comenzó de responder:

-"Ven acá, el pastorcico, si quieres tomar placer; siesta es de mediodía, que ya es hora de comer; si querrás tomar posada todo es a tu placer". -“Que no era tiempo, señora, que me haya de detener; que tengo mujer e hijos, y casa que mantener...". -"Vete con Dios, pastorcillo, no te sabes entender, hermosuras de mi cuerpo yo te las hiciera ver...".
}

\footnotetext{
${ }^{16}$ Me refiero con esto a los dos primeros libros, ya que en el tercero la tópica aparece representada en forma, como siempre, denigratoria, por la sospecha metódica que despierta en la mujer: "Mulier enim neminem confidit amicum et quemlibet credit penitus deceptorem..." (III, 86).
} 
Hasta en el Romance del conde Alarcos la infanta Solisa se dirige al padre solicitando sin vergüenza el objeto de su amor; y en el Romance que dice: de Francia partió la niña, o de la Infantina, y de Gerineldo. El caso más extremo queda el de la linda Melisenda, con asesinato incluido.

Extrañamente, en el tratado medieval el tema no queda caracterizado sino como el omnipresente reproche a la mujer, bajo la forma de pecado capital: la mujer nunca expulsaría de su cama a hombre alguno, por más que tenga un marido noble y gentil ${ }^{17}$ (clara inversión, tal vez irónica, de las palabras atribuidas a la noble mujer enamorada del marido, en el diálogo del "más noble" con ella): es decididamente procaz, y llena de lujuria. Pero en el cuerpo del tratado, donde naturalmente se aspira a la igualdad de oportunidades y derechos en materia sexual, nunca sucede que a la mujer se confíe un rol protagónico de conquista; la mujer debe cribar y discernir, tiene en todo momento el dominio de la situación, domina, argumenta, escoge: su guarda es de naturaleza intelectual, no suspicazmente impuesta o victimariamente requerida. La conclusión es inevitable: cuando un núcleo aparece exitosamente dramatizado en el romancero, encontrará su teorización cumplida -exenta, por tanto, de caracterizaciones pragmáticas- por obra del tratadista medieval. Solo la modalidad teórica cambia: lineal, en los primeros dos libros, por recogida directa de la tradición; metódicamente desplazada, hasta las tortuosidades del exceso monolítico, en la vertiente negativa del De Amore.

\section{Referencias}

Alighieri, D. (1979). Opere minori. II. Monarchia. B. Nardi (Ed.). Ricciardi.Milano-Napoli.

Alvar, M. (1970). El romancero. Tradicionalidad y pervivencia. Planeta. Barcelona.

Anahory-Librowicz, O. (1989). "Las mujeres no-castas en el romancero: un caso de honra". En S. Neumeister, Actas del IX Congreso de la Asociación Internacional de Hispanistas. Vervuert. Madrid. CCCXXI-CCCXXX.

Botta: (2013). "El léxico del Romancero General de 1600”. Edad de oro. 32. 47-78.

Cano, B. (2004). "Las mujeres malas en el Romancero". En Líneas actuales de investigación literaria: estudios de literatura hispánica. Universidad. Valencia. LXIII-LXXI.

Capellanus, A. (1982). De Amore. P.G. Walsh (Ed.). Duckworth. London.

Cherchi: (1994). The Ambiguity of Courtly Love in Andreas Capellanus's Model. University Press. Totonto.

Cherchi: (2016). "Acursar les faldes". Postilla al Tirant Lo Blanch, cap. XIV. Studi Romanzi. Nuova serie. 12. 233-243.

Di Patre: (2018). "A la sombra del De Amore. Dante entre Capellanus y La Celestina”. Celestinesca. 42. 57-82.

Di Patre: (2018). "Dalla Monarchia di Dante al trattato machiavelliano sul Principe: un percorso obbligato". Dante. Rivista internazionale di studi su Dante Alighieri. XV. 11-28.

González Troyano, A. (1989). "Algunos rasgos del arquetipo de la mujer seductora en el romancero tradicional andaluz”. En Pedro M. Piñero Ramírez. El Romancero. Tradición y pervivencia en el siglo $X X$. Fundación Machado de Cádiz. Sevilla.

${ }^{17}$ De Amore, III, 105. 
Lacarra Lanz, M.E. (1993). "Representaciones de mujeres en la literatura española de la Edad Media (escrita en castellano)". En Iris M. Zavala. Breve historia feminista de la literatura española en lengua castellana. 2. Ánthropos. Madrid. XXI-LXVIII.

Martínez, N. (2015). “Andrés el Capellán ante el fenómeno del amor cortés”. Studium. Filosofía y Teología. 35. 101-107.

Paolini, D. (2010). "El libro de buen amor y el amor descortés". En P. Civil, F. Crémoux, Nuevos Caminos del hispanismo. Actas del XVI Congreso de la Asociación Internacional de Hispanistas. 2. Iberoamericana. Madrid. XXXXVI-LII.

Romancero (1984). M. Alvar (Ed.). Bruguera. Barcelona.

Romancero (1994). P. Díaz-Mas (Ed.). Editorial Crítica. Barcelona.

Villas Millanes G. (2020). La mujer en el romancero: una propuesta de análisis tipológico de los personajes femeninos. [Disertación de grado, Universidad de Zaragoza]. https://zaguan.unizar.es/record/94789/files/TAZ-TFG-2020-1108.pdf?version=1. 